\title{
Noël Audet, Le roi des planeurs
}

\section{Simona Rossi}

\section{(Q) OpenEdition}

\section{Journals}

\section{Edizione digitale}

URL: http://journals.openedition.org/studifrancesi/28228

DOI: 10.4000/studifrancesi.28228

ISSN: 2427-5856

\section{Editore}

Rosenberg \& Sellier

\section{Edizione cartacea}

Data di pubblicazione: 31 décembre 2006

Paginazione: 650

ISSN: 0039-2944

\section{Notizia bibliografica digitale}

Simona Rossi, « Noël Audet, Le roi des planeurs », Studi Francesi [Online], 150 (L | III) | 2006, online dal

30 novembre 2015, consultato il 08 novembre 2020. URL : http://journals.openedition.org/

studifrancesi/28228; DOI : https://doi.org/10.4000/studifrancesi.28228

\section{Questo documento è stato generato automaticamente il 8 novembre 2020.}

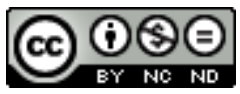

Studi Francesi è distribuita con Licenza Creative Commons Attribuzione - Non commerciale - Non opere derivate 4.0 Internazionale. 


\title{
Noël Audet, Le roi des planeurs
}

\author{
Simona Rossi
}

\section{NOTIZIA}

NOËL AUDET, Le roi des planeurs, Montréal, XYZ éditeur, 2005, pp. 200.

1 Un giovane e ingenuo pilota di deltaplano accusato di omicidio, la morte misteriosa di Mélissa, una ragazza di appena sedici anni, lo strano legame intrattenuto da quest'ultima con le sue amiche, piccole "streghe" del Duemila, affascinate dalle forze del male e dai poteri ultraterreni: l'ultimo romanzo di Noël Audet è una sorta di appassionante labirinto all'interno del quale non è affatto facile districarsi. La storia comincia nel momento in cui Loubert, il pilota, è rinchiuso in un ospedale psichiatrico, dopo la dimostrazione, da parte del suo avvocato, della sua infermità mentale. Attraverso il processo, però, e soprattutto attraverso gli incontri tra Loubert e Cristelle, la migliore amica della defunta Mélissa, a poco a poco si ricostruisce tutta la vicenda. Il lettore scopre, così, diversi dettagli: ad esempio i macabri piani di un gruppo di giovani donne legate tra loro dal patto della Rosa Nera, che prevede, per una delle adepte tirata a sorte, l'esperienza della morte; l'insaziabile fame d'amore di Mélissa, che prima di gettarsi nel vuoto dal piccolo deltaplano che ha scelto come veicolo dell'oblio, arde dal desiderio di conoscere l'amore fisico; l'ingenuità e l'incredibile bisogno di tenerezza di Loubert, segnato da un rapporto arido e conflittuale con la madre. Loubert s'innamorerà a prima vista di Mélissa e sarà proprio lui, ignaro delle intenzioni della giovane, a condurla verso la morte, a vedere il suo corpicino esile e bianco precipitare nel vuoto come una farfalla senza ali.

2 Attorno all'ingarbugliata vicenda si muovono mille personaggi-fantocci, talvolta senza nome, pazzi, omicidi, incompresi, colpevoli, innocenti, i quali ascoltano Loubert e lo consolano, aiutandolo a farsi coraggio e a non dubitare di se stesso. Fino all'epilogo, quando, svelato il mistero della Rosa Nera, un giudice riconoscerà l'innocenza di Loubert e gli permetterà di tornare ad essere le roi des planeurs. La vicenda termina proprio in volo, con una scena magistrale, che vede Loubert e Cristelle rendere omaggio 
a Mélissa sul piccolo deltaplano, trasportati da un vento turbinoso e profumato. L'aria, del resto, metafora dell'aspetto aleatorio dell'esistenza umana, è la vera protagonista del libro, che costituisce il primo volume di una trilogia ancora da completare: il secondo tratterà il fuoco e l'impetuosità dell'amore, mentre il terzo l'acqua, simbolo dello scorrere della vita, dalla nascita al "naufragio" finale.

3 Tra il romanzo poliziesco e quello d'amore, Noël Audet ci regala un'opera lucida ed affascinante, all'interno della quale umorismo noir, dolcezza e pazzia si mescolano per processare un uomo, ma forse il mondo intero, che, travolto da una folle corsa, non distingue più il bene dal male. 